Jurnal Abdimas Berdaya : Jurnal Pembelajaran, Pemberdayaan dan Pengabdian Masyarakat Volume 4 Nomor 01 Tahun 2021

\title{
Pelatihan Pemberdayaan Perpustakaan Sekolah Sebagai Upaya Meningkatkan Proses Pembelajaran di SMP Negeri 25 Kabupaten Kerinci
}

\section{Training and Empowerment of Scholl Library as an Effort to Improve the Learning Process at SMP Negeri 25 Kabupaten Kerinci}

\author{
Sofyan $^{1}$, Bradley Setiyadi ${ }^{2}$, Sophia Rahmawati ${ }^{3}$ \\ ${ }^{123}$ Universitas Jambi \\ e-mail: ${ }^{1}$ sofyansorry61@ gmail.com, ${ }^{2}$ bradleysetiyadi@unja.ac.id, \\ ${ }^{3}$ sophiarahma9@gmail.com
}

\begin{abstract}
Abstrak: Perpustakaan sekolah dapat dimanfaatkan sebagai bagian dari layanan terhadap minat baca siswa serta berperan sebagai pusat sumber belajar siswa. Dimana keberadaan perpustakaan ini dapat memberikan serta menyediakan bahan-bahan bacaan ataupun materi pelajaran bagi siswa. Dalam proses pembelajaran diharapkan perpustakaan dapat membantu siswa untuk menghasilkann karya yang bermutu, perpustakaan tidak bisa bekerja sendiri. Dukungan sekolah, terutama melalui kebijakan kepala sekolah, akan memperlancar tugas atau kebijakan yang akan dijalankan oleh pengelola perpustakaan sekolah. Permasalahan utama menjadi mitra kegiatan pengabdian ini adalah masyarakat sekolah harus produktif sehingga menghasilkan pelayanan perpustakaan yang efektif. Namun terdapat kendala dalam pengelolaan perpustaan di sekolah yang merupakan implementasi dari kegiatan ini antara lain: (1) belum maksimalnya peran perpustakaan dengan baik, (2) masih terbatasnya pengetahuan pengelola tentang peran perpusatkaan, (3) kurangnya motivasi siswa dalam memanfaatkan perpustakaan sebagai sumber belajar. Metode yang digunakan dalam pelaksanaan program pelatihan pengelola perpustakaan ini adalah metode kaji tindak partisipatif karena program pelatihan ini dilakukan sebagai upaya meningkatkan pemberdayaan perpustakaan sekolah di SMP Negeri 25 Kabupaten Kerinci sebagai upaya meningkatkan proses belajar.
\end{abstract}

Kata Kunci: pelatihan, pemberdayaan, perpustakaan sekolah, pembelajaran

Abstract: The school library can be used as part of a service to students' interest in reading and serves as a center for student learning resources. Where the existence of this library can provide and provide reading materials or subject matter for students. In the learning process it is hoped that libraries can help students to produce quality work, libraries cannot work alone. School support, especially through the principal's policy, will facilitate the tasks or policies that will be carried out by the school library manager. The main problem being a partner of this community service activity is that the school community must be productive so as to produce an effective library service. However, there are obstacles in managing library in schools which are the implementation of this activity, among others: (1) the role of libraries has not been maximized, (2) the manager's knowledge is still limited about the role of library, (3) the lack of student motivation in using the library as a learning resource. The method used in the implementation of the library manager training program is a participatory action review method because the training program is carried out as an effort to increase the empowerment of school libraries in SMP Negeri 25 Kabupaten Kerinci as an effort to improve the learning process.

Keywords: training, empowerment, school library, learning 


\section{A. Pendahuluan}

Perpustakaan sekolah merupakan sarana pendidikan yang perlu mendapat perhatian khusus oleh pengelola pendidikan. Kata perpustakaan berasal dari kata pustaka, yang berarti kitab, buku-buku, kitab primbon (Depdikbud, 2006). Selain itu, perpustakaan adalah salah satu unit kerja yang berupa tempat untuk mengumpulkan, menyimpan, mengelola, dan mengatur koleksi bahan pustaka secara sistematis untuk digunakan oleh pemakai sebagai sumber informasi sekaligus sebagai sarana belajar yang menyenangkan. Jika dikaitkan dengan proses belajar mengajar, perpustakaan sekolah memberikan sumbangan yang sangat berharga dalam upaya meningkatkan prestasi siswa serta meningkatkan kualitas pendidikan dan pengajaran. Fasilitas penyediaan perpustakaan, siswa dapat berinteraksi dan terlibat langsung baik secara fisik maupun mental dalam proses belajar. Perpustakaan sekolah juga bagian integral dari program sekolah secara keseluruhan, dimana bersama-sama dengan komponen pendidikan lainnya turut menentukan keberhasilan proses pendidikan dan pengajaran. Dalam Undang-Undang Sisdiknas 2003 dijelaskan bahwa tidak hanya interaksi peserta didik dan pendidik saja, melainkan juga sumber belajar. Sumber belajar diartikan sebagai segala tempat atau lingkungan sekitar, benda, dan orang yang mengandung informasi dapat digunakan sebagai wahana bagi peserta didik untuk melakukan proses perubahan perilaku. Salah satu sumber belajar yang terdapat dalam lingkungan sekolah adalah berupa perpustakaan sekolah. Perpustakaan sebagai sumber belajar ini memang wajib dimiliki oleh setiap sekolah. Sementara Undang-Undang Perpustakaan Nomor 43 tahun 2007 menyebutkan bahwa setiap lembaga pendidikan wajib menyelenggarakan perpustakaan yang memenuhi standar nasional perpustakaan dengan memperhatikan Standar Nasional Pendidikan.

Perpustakaan sekolah dapat dimanfaatkan sebagai bagian dari layanan terhadap minat baca siswa serta berperan sebagai pusat sumber belajar siswa. Keberadaan perpustakaan ini dapat memberikan serta menyediakan bahan-bahan bacaan ataupun materi pelajaran bagi siswa. Dalam proses pembelajaran diharapkan perpustakaan dapat membantu siswa untuk menghasilkann karya yang bermutu, perpustakaan tidak bisa bekerja sendiri. Dukungan sekolah, terutama melalui kebijakan kepala sekolah, akan memperlancar tugas atau kebijakan yang akan dijalankan oleh pengelola perpustakaan sekolah. Tugas perpustakaan dalam memajukan masyarakat sekolah melalui ilmu pengetahuan dan informasi harus diwujudkan secara efektif dan efisien. Masyarakat sekolah yang menjadi sasaran perpustakaan, dapat memanfaatkan perpustakaan dengan efektif. Khususnya siswa, yang menjadi obyek dari pada pembelajaran dan pengajaran, harus dikenalkan betapa pentingnya manfaat dari perpustakaan sekolah.

Perpustakaan sekolah dapat diartikan sebagai perpustakaan yang berada pada lembaga pendidikan sekolah, yang merupakan bagian integral dari sekolah yang bersangkutan dan merupakan sumber belajar untuk mendukung tercapainya tujuan pendidikan sekolah yang bersangkutan. Keberadaan perpustakaan sekolah memiliki 
peranan yang sangat penting. Salah satunya adalah peranan perpustakaan sekolah sebagai sumber belajar. (Sumiati, 2012:16). Sementara Sardiman (2007:262) berpendapat bahwa, macam sumber yang ada di luar diri seseorang (peserta didik) dan yang memungkinkan atau memudahkan terjadinya proses belajar disebut sebagai sumber belajar.

Permasalahan utama menjadi mitra kegiatan pengabdian ini adalah masyarakat sekolah harus produktif sehingga menghasilkan pelayanan perpustakaan yang efektif. Namun terdapat kendala dalam pengelolaan perpustaan di sekolah yang merupakan implementasi dari kegiatan ini antara lain: (1) belum maksimalnya peran perpustakaan dengan baik, (2) masih terbatasnya pengetahuan pengelola tentang peran perpusatkaan, (3) kurangnya motivasi siswa dalam memanfaatkan perpustakaan sebagai sumber belajar. Disinilah peran melatih dan membina guna menumbuhkan motivasi siswa dalam memanfaatkan perpustakaan sebagai sumber belajar. Dengan melihat kondisi yang di sekolah, maka menjadi sebuah kepentingan untuk melakukan pelatihan dan pembinaan kepada para pengelola perpustakaan dan masyarakat sekolah. Pelatihan atau workshop ini dilakukan dalam upaya perpustakaan sekolah agar dapat dijadikan sebagai bagian dari layanan terhadap minat baca siswa serta berperan sebagai pusat sumber belajar siswa khususnya dan masyarakat sekolah pada umumnya.

Tujuan dilaksanakannya workshop pembinaan dan pelatihan ini diharapkan mampu menjadikan perpustakaan sebagai sarana pelestarian bahan pustakaan, manfaat perpustakaan sebagai sumber informasi ilmu pengetahuan, teknologi dan kebudayaan, serta tujuan perpustakaan untuk mencerdaskan kehidupan bangsa dan menunjang pembangunan nasional. Oleh karena itu, workshop dilaksanakan untuk memberikan pengetahuan pemberdayaan perpustakaan sekolah dimana sebagai upaya meningkatkan proses pembelajaran oleh guru. Pengelola atau petugas perpustakaan yang memiliki kecakapan khusus dalam menggunakan pedoman pengolahan bahan perpustakaan yang baku, seperti Dewey Decimal Classification (DDC) untuk pengklasifikasian buku, Anglo American Cataloging Rules (AACR) untuk pengkatalogan, dan Pedoman Tajuk Subjek untuk penentuan subjek buku di SMP Negeri 25 Kabupaten Kerinci. Sebagai rencana awal workshop maka peserta perlu memahami skema tujuan perpustakaan sekolah. Masyarakat sekolah harus memahami skema tujuan diatas, sehingga perpustakaan sekolah memiliki peran dalam meningkatkan proses belajar baik oleh guru maupun siswa. Skema tujuan perpustakaan sekolah digambarkan sebagai berikut. 


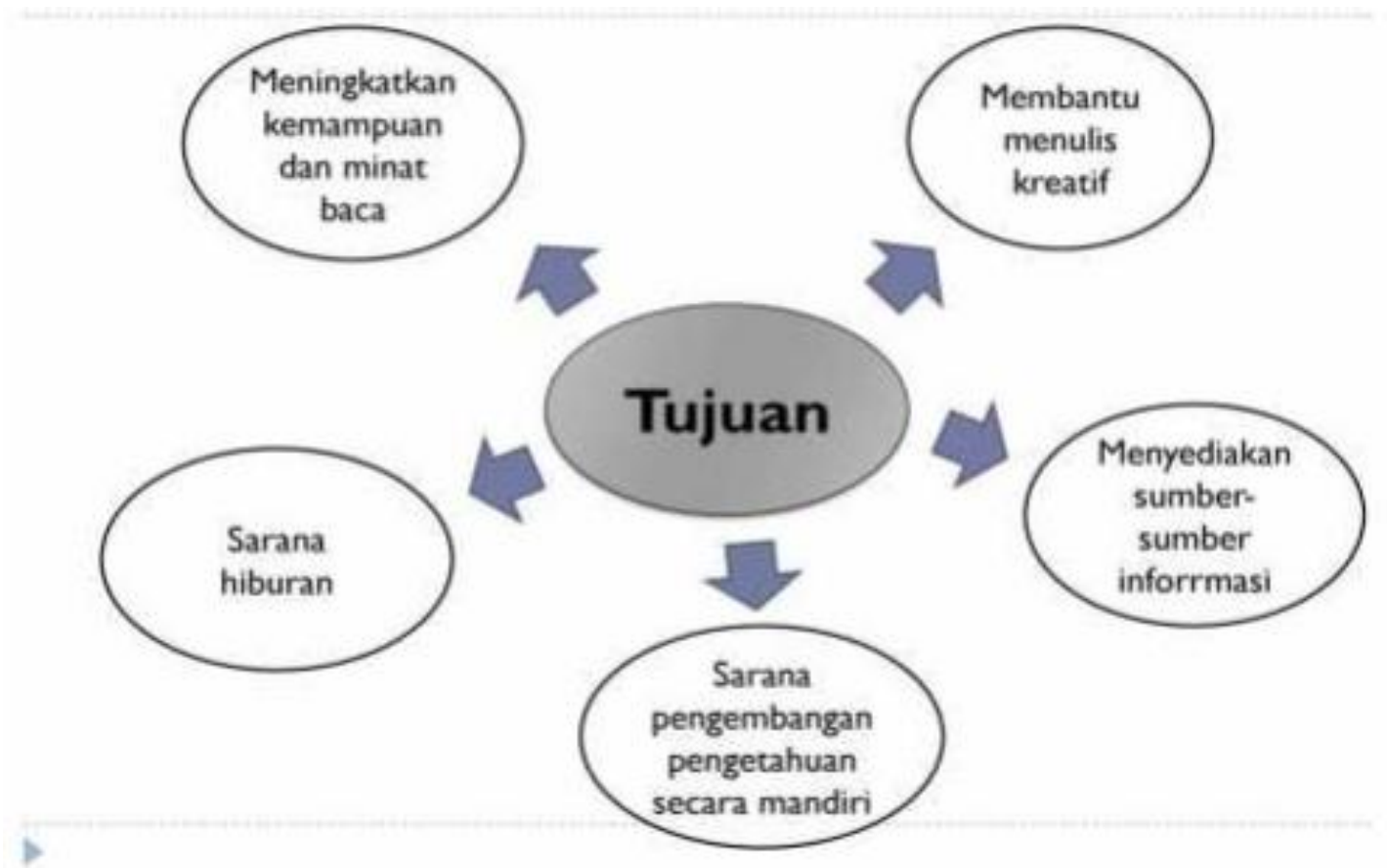

Gambar 1. Skema Tujuan Perpustakaan Sekolah

\section{B. Metode}

Kegiatan pelaksanaan pengabdian masyarakat ini dilaksanakan di SMP Negeri 25 Kabupaten Kerinci yang terletak di Desa Pelompek, Kecamatan Gunung Tujuh, Kabupaten Kerinci. Metode yang digunakan dalam pelaksanaan program pelatihan pengelola perpustakaan ini adalah metode kaji tindak partisipatif karena program pelatihan ini dilakukan sebagai upaya meningkatkan pemberdayaan perpustakaan sekolah di SMP Negeri 25 Kabupaten Kerinci dalam upaya meningkatkan proses belajar. Dengan menggunakan metode kaji tindak partisipatif diharapkan dapat menciptakan keyakinan bahwa masyarkat sekolah mampu memberdayakan perpustakaan untuk meningkatkan proses belajar. Metode yang akan digunakan dalam program pengabdian mayarakat Integratif ini adalah melalui: a) metode ceramah; b) metode integratif teoritis, pengalaman praktis dan praktek atau praktek demonstrasi (berdasarkan materinya); c) serta tutorial melalui pendekatan manajemen praktis (manajemen perpustakaan sekolah, pemanfaatan ICT, dan sebagainya), manajemen sumber-sumber belajar (berdasarkan substansinya). Realisasi yang dilakukan adalah sebagai berikut:

1. Memahami pemberdayaan perpustakaan sekolah untuk meningkatkan proses belajar oleh seluruh masyarakat sekolah, sehingga perpustakaan sekolah memiliki perannya di dukung oleh sarana dan prasarana sekolah.

2. Menumbukan minat baca bagi siswa. Pada saat workshop peserta diajak berdiskusi dan berpartisipasi aktif topik literasi. Selain itu penggunaan kata dan 
pola diskusi yang mampu diterima oleh peserta memberikan mereka semangat dan antusiasme dalam mengikuti kegiatan samapai akhir.

3. Terciptanya Manajemen perpustakaan bagi pengelola perpustakaan sekolah berdasarkan manajemen yang baik Pertemuan dan diskusi antara peserta. Penjelasan ini berguna agar peserta pelatihan menyadari dan mampu merencanakan, mengatur, mengorganisasikan dan mengimplementasikan bagaimana manajemen perpustakaan dengan prinsip manajemen yang baik sehingga dapat meningkatkan pemberdayaan perpustakaan di sekolah untuk meningkatkan proses belajar.

Tabel 1. Tahapan Materi Pelatihan

\begin{tabular}{|c|c|c|}
\hline No & Materi Pelatihan & Tujuan Pelatihan \\
\hline 1 & Tahap 1 & $\begin{array}{l}\text { a) Kurikulum dan pembelajaran di perpustakaan } \\
\text { b) Pengantar literasi informasi di perpustakaan } \\
\text { c) Pemanfaatan TIK di perpustakaan } \\
\text { d) Manajemen perpustakaan di sekolah } \\
\text { e) Hakikat perpustakaan sekolah } \\
\text { f) Sumber-sumber belajar }\end{array}$ \\
\hline 2 & Tahap 2 & 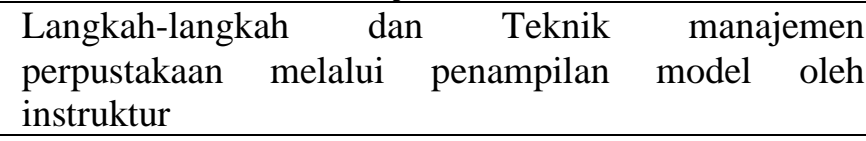 \\
\hline 3 & Tahap 3 & $\begin{array}{l}\text { Pemanfaatan TIK oleh peserta terhadap peserta lain } \\
\text { secara bergiliran }\end{array}$ \\
\hline 4 & Tahap 4 & Diskusi dan Evaluasi \\
\hline 5 & Tahap 5 & Penentuan rencana tindak \\
\hline
\end{tabular}

\section{Hasil dan Pembahasan}

Pelaksanaan pengabdian masyarakat berupa pelatihan pemberdayaan perpustakaan sekolah di SMP Negeri 25 Kabupaten Kerinci adalah sebagai berikut:

Tabel 2. Materi Pelatihan dan Instruktur

\begin{tabular}{clll}
\hline No & \multicolumn{1}{c}{ Materi Pendampingan } & & \multicolumn{1}{c}{ Penanggung Jawab Program } \\
\hline 1 & Sosialisasi dan pendaftaran & 1. & Sophia Rahmawati, S.Pd., M.Pd \\
\hline 2 & a) Materi Manajemen Perpustakaan & & \\
& b) Pemanfaatan ICT & & \\
& c) Manajemen Sumber-sumber & 1. & Dr. Sofyan, S.Pd., M.Pd \\
& Belajar & 2. & Keynote Speaker \\
& d) Pengantar Literasi di Perpustakaan & & \\
& e) Kurikulum dan Pembelajaran di & & \\
& Perpustakaan & & \\
\hline 3 & Presentasi Pemberdayaan Perpustakaan & 1. & Sophia Rahmawati, S.Pd., M.Pd \\
& di Sekolah & & \\
\hline 4 & Pendampingan Pemberdayaan & 1. & Dr. Sofyan, S.Pd., M.Pd \\
& Perpustakaan di Sekolah & 2. Sophia Rahmawati, S.Pd., M.Pd \\
\hline
\end{tabular}


Lokasi SMP Negeri 25 Kabupaten Kerinci sangatlah strategis, karena berada di bawah kaki Gunung Tujuh serta berapa pada sisi lintasan Jalan Raya Sungai Penuh Padang. Oleh karena itu, memahami pemberdayaan perpustakaan sekolah untuk meningkatkan proses belajar sangat penting bagi seluruh masyarakat sekolah, sehingga perpustakaan sekolah memiliki perannya dengan dukungan dari sarana dan prasarana sekolah. Perpustakaan sekolah sangat penting untuk menumbuhkan minat baca bagi siswa berkaitan dengan perannya sebagai pusat kegiatan literasi. Pada saat workshop peserta diajak berdiskusi dan berpartisipasi aktif topik literasi. Selain itu pola diskusi yang mampu diterima oleh peserta memberikan mereka semangat dan antusiasme dalam mengikuti kegiatan sampai akhir untuk memahami bagaimana mewujudkan manajemen perpustakaan bagi pengelola perpustakaan sekolah berdasarkan manajemen yang baik.

Perpustakaan sekolah bertujuan untuk menyerap dan menghimpun informasi, mewujudkan suatu wadah pengetahuan yang terorganisir, membantu perkembangan kecakapan bahasa dan daya pikir, mendidik murid agar dapat menggunakan dan memelihara bahan pustaka secara efisien serta memberikan dasar ke arah studi mandiri. (Darmono, 2007: 7). Penjelasan ini berguna agar peserta pelatihan menyadari dan mampu merencanakan, mengatur, mengorganisasikan dan mengimplementasikan bagaimana manajemen perpustakaan dengan prinsip manajemen yang baik sehingga dapat meningkatkan pemberdayaan perpustakaan di sekolah untuk meningkatkan proses belajar.

Untuk mewujudkan perpustakaan sesuai dengan fungsi dan peranannya, maka perpustakaan diperlukan suatu manajemen pengelolaan yang sesuai standar nasional dalam mengelola perpustakaan, karena tanpa manajemen yang baik, maka pekerjaan tidak akan berjalan sesuai dengan apa yang diharapkan. Agar perpustakaan sekolah masih tetap menjadi pilihan utama untuk memperoleh informasi, hal yang harus diperhatikan adalah manajemen perpustakaan yang meliputi kegiatan pengadaan, sistem layanan perpustakan dan pengelolaan bahan koleksi. Pengelola perpustakaan sekolah dituntut untuk dapat memberikan pelayanan yang dapat memuaskan keinginan pengguna perpustakaan. Bentuk pelayanan yang dapat diberikan berupa keramahan, tanggap serta cepat dalam melayani setiap keluhan ataupun pertanyaan. (Efrina dkk, 2017:518). Perpustakaan sekolah merupakan salah satu sarana dalam mengembangkan pengetahuan, keterampilan, dan sikap murid-murid. Ruang dan perlengkapan yang tersedia harus ditata dan dirawat dengan baik sehingga benar-benar menunjang penyelenggaraan perpustakaan sekolah yang efektif dan efisien. (Pratama dkk, 2018:84).

Pengelola perpustakaan dapat memberikan kegiatan-kegiatan yang bermanfaat, sehingga siswa dan guru dapat bergairah untuk berkunjung dan memanfaatkan perpustakaan sebagai sumber belajar. Untuk mewujudkan manajemen perpustakaan yang baik, maka pengelola perpustakaan maka pengelola perlu mengembangkan kemampuan professional sebagai pustakawan, memperhatikan kemampuan yang diperlukan dan prosedur yang dibutuhkan untuk dapat mengelola perpustakaan secara 
efektif, dari perpustakaan yang sekedar bertahan hidup menjadi perpustakaan yang benar-benar berjalan secara baik, mengembangkan kebijakan dan prosudur dengan prinsip-prinsip yang mengaktualisasikan visi dari perpustakaan sekolah, memperlihatkan keterkaitan antar sumber-sumber informasi dan tujuan dan prioritas sekolah serta program perpustakaan dan menunjukan peran guru dan pustakawan melalui rencana manajemen. (Herman, 2006:20).

Kegiatan-kegiatan yang dilaksanakan dalam pengabdian pelatihan dan pemberdayaan perpustakaan sekolah di SMP Negeri 25 Kabupaten Kerinci ditampilkan pada gambar-gambar berikut

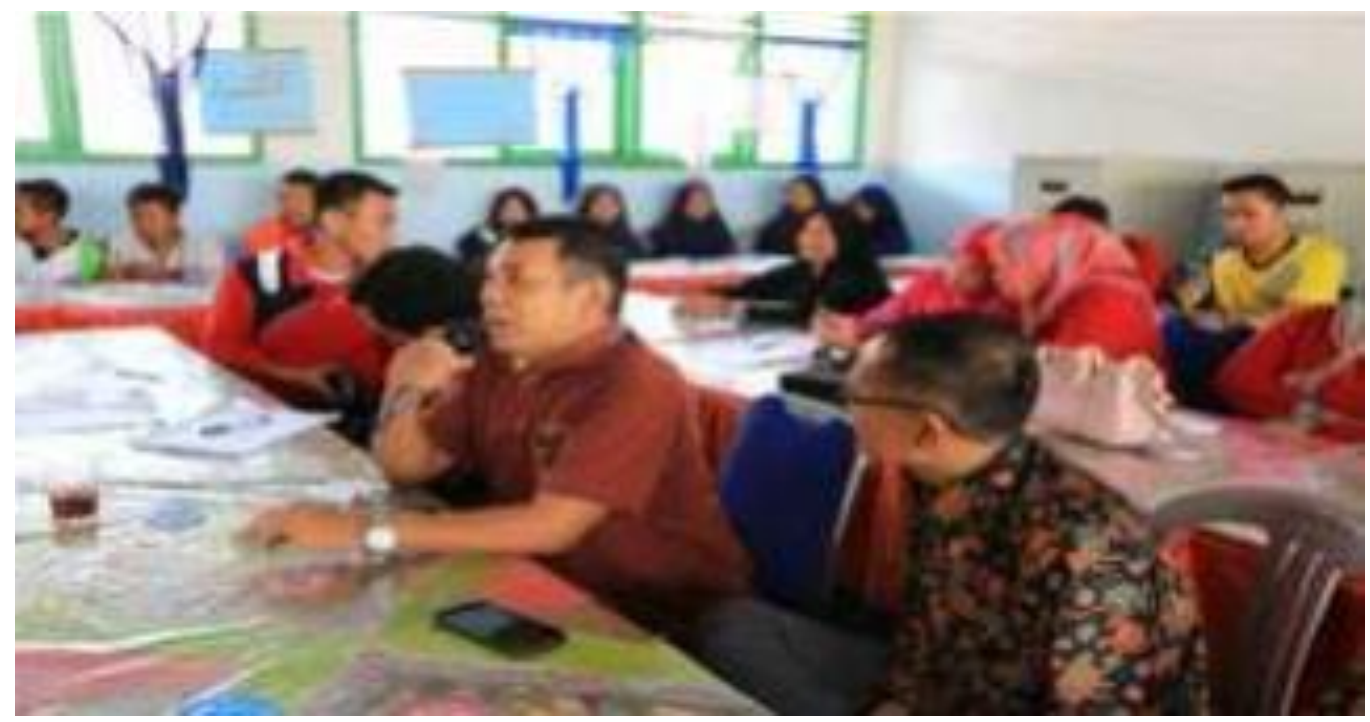

Gambar 2. Kepala Sekolah Menjelaskan Kondisi Perpustakaan Sekolah

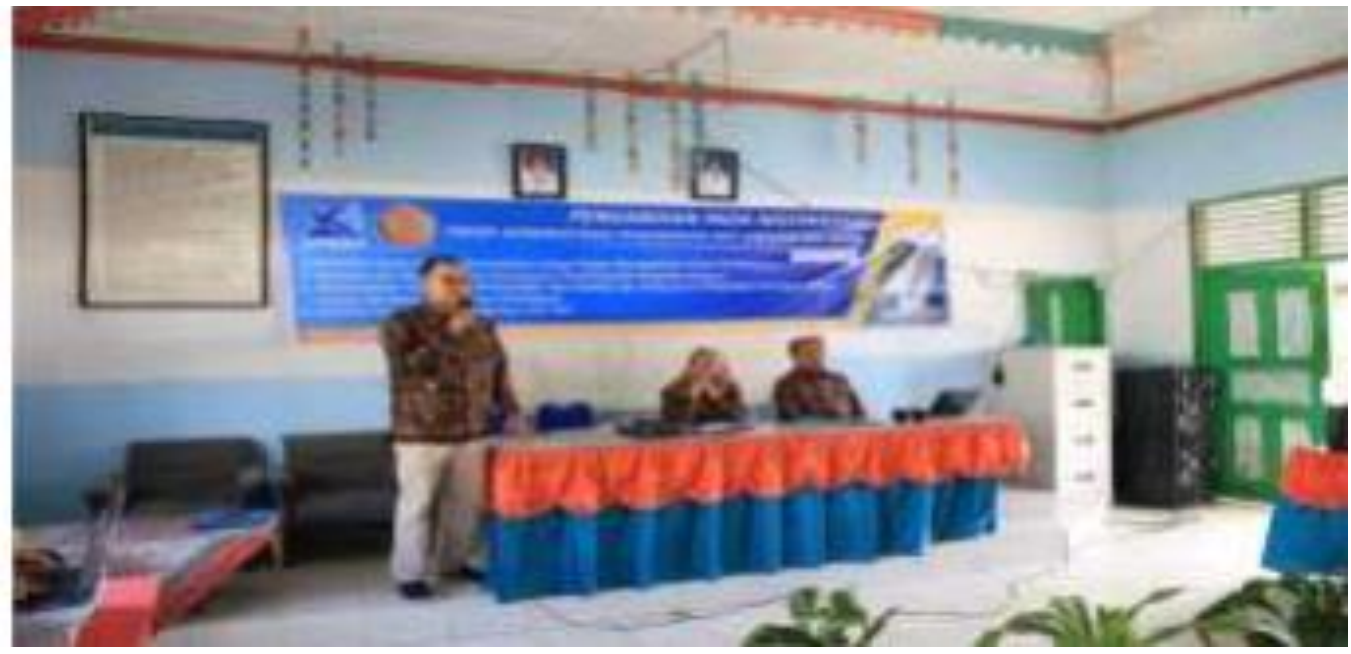

Gambar 3. Narasumber Memberikan Materi

Adapun materi-materi yang diberikan oleh Materi Manajemen Perpustakaan berupa Pemanfaatan ICT, Manajemen Sumber-Sumber Belajar, Pengantar Literasi di Perpustakaan, Kurikulum dan Pembelajaran di Perpustakaan merupakan suatu 
pengetahuan juga keterampilan yang mendasar untuk dipahami sekaligus diterapkan oleh pengelola perpustakaan sekolah di SMP Negeri 25 Kabupaten Kerinci. Keberadaan perpustakaan ini harus memberikan dan menyediakan bahan-bahan bacaan ataupun materi pelajaran bagi siswa. Sehinngga siswa tertarik untuk berkunjung ke perpustakaan. Dalam proses pembelajaran diharapkan perpustakaan dapat membantu siswa untuk menghasilkan karya yang bermutu, kreatif, inovatif dan berkarakter.

Pelayanan merupakan unsure utama dalam pencapaian suatu keberhasilan organisasi perpustakaan disebabkan bagian inilah yang berhubungan langsung dengan pengguna dalam penyebaran informasi serta pemanfaatan jasa dan fasilitas yang ada di perpustakaan. Layanan perpustakaan merupakan tolak ukur keberhasilan sebuah perpustakaan. Jenis layanan perpustakaan sekurang-kurangnya meliputi (1) layanan baca di tempat, (2) layanan sirkulasi, (3) layanan referensi (4) layanan teknologi dan informasi. Standar koleksi perpustakaan meliputi, (1) buku (buku teks, buku penunjang kurikulum, buku bacaan, buku referensi dan buku biografi). (2) terbitan berkala (majalah, surat kabar), (3) audio visual, (4) layanan teknologi informasi dan komunikasi. Perpustakaan sekolah akan dapat berfungsi sebagai sumber informasi dan sumber belajar apabila tersedia bahan pustaka yang bermacammacam jenisnya dan memiliki jumlah yang banyak, selain itu disesuaikan dengan kebutuhan pemustaka dan diminati oleh pemustaka.

\section{Simpulan}

Perpustakaan adalah salah satu unit kerja yang berupa tempat untuk mengumpulkan, menyimpan, mengelola, dan mengatur koleksi bahan pustaka secara sistematis untuk digunakan oleh pemakai sebagai sumber informasi sekaligus sebagai sarana belajar yang menyenangkan. Jika dikaitkan dengan proses belajar mengajar, perpustakaan sekolah memberikan sumbangan yang sangat berharga dalam upaya meningkatkan prestasi siswa serta meningkatkan kualitas pendidikan dan pengajaran. Fasilitas penyediaan perpustakaan, siswa dapat berinteraksi dan terlibat langsung baik secara fisik maupun mental dalam proses belajar. Perpustakaan sekolah juga bagian integral dari program sekolah secara keseluruhan, dimana bersama-sama dengan komponen pendidikan lainnya turut menentukan keberhasilan proses pendidikan dan pengajaran.

Kegiatan ini memberikan dampak positif terhadap masyarakat sekolah yang harus produktif sehingga menghasilkan pelayanan perpustakaan yang efektif maka dari itu perlu dilakukan kesinambungannya dan tidak hanya saja pada pengelola perpustakaan namun melibatkan semua masyarakat sekolah dengan melakukan kegiatan dan melibatkan semua masyarakat sekolah agar perpustakaan akan meningkatkan proses pembelajaran 


\section{Ucapan Terima Kasih}

Universitas Jambi sebagai Perguruan Tinggi Negeri merupakan salah satu tempat untuk mendidik kader-kader pembangunan melalui Tridharmanya yang meliputi proses pendidikan dan pengajaran, penelitian, dan pengabdian pada masyarakat berkerja sama dengan semua pihak ikut serta dalam mengisi pembangunan, untuk mengabdikan diri secara nyata dalam membantu pemerintah dalam mencerdaskan masyarakat dalam pembangunan. Sebagai wujud pengabdian pada masyarakat Universitas Jambi merupakan lembaga yang sangat kompeten dalam program pengabdian masyarakat berupa pembinaan dan pelatihan dalam meningkatkan pemberdayaan perpustakaan sekolah di SMP Negeri 25 Kabupaten Kerinci sebagai upaya meningkatkan proses belajar. Terima kasih kami ucapkan sebesar-besarnya kepada pihak LPPM (Lembaga Penelitian dan Pengabdian Masyarakat (LPPM) Universitas Jambi yang telah memberikan bantuan berupa dana hibah kegiatan pengabdian masyarakat melalui skema Penerimaan Negara Bukan Pajak (PNBP) Fakultas Keguruan dan Ilmu Pendidikan (FKIP). 


\section{Daftar Rujukan}

Darmono. 2007. Pengembangan Perpustakaan Sekolah sebagai Sumber Belajar. Jurnal Perpustakaan Sekolah Volume 1 Nomor 1 April 2017 hal. 1-10.

Departemen Pendidikan dan Kebudayaan. 2006. Pengantar Ilmu Perpustakaan. Jakarta: Sagung Seto.

Efrina, Median; R.N. Sasongko dan Zakaria. 2017. Pengelolaan Perpustakaan Sekolah. Manajer Pendidikan Volume 11 Nomor 6 Juli 2017 hal. 517.524.

Herman, S.R. 2006. Etika Kepustakawanan: Suatu Pendekatan terhadap Profesi dan Etika Pustakawan Indonesia. Jakarta: Sagung Seto.

Pratama, Adhitya Surya; Roemintiyono dan S.Sumarni. 2018. Analisis Pengelolaan Perpustakaan Sekolah (Studi Kasus pada Perpustakaan SMK Negeri 2 Surakarta). IJCEE Volume 4 Nomor 2 Desember 2018 hal. 82-92.

Sardiman, A.M. 2007. Interaksi dan Motivasi Belajar Mengajar. Jakarta: Raja Grafindo Persada.

Sumiati, Opung. 2012. Pengelolaan Perpustakaan Sekolah. Jakarta: Universitas Terbuka.

Undang-Undang Republik Indonesia Nomor 20 Tahun 2003 tentang Sistem Pendidikan Nasional. Lembaran Negara Republik Indonesia Tahun 2003 Nomor 78, Tambahan Lembaran Negara Republik Indonesia Nomor 4301.

Undang-Undang Republik Indonesia Nomor 43 Tahun 2007 tentang Perpustakaan. Lembaran Negara Republik Indonesia Tahun 2007 Nomor 129, Tambahan Lembaran Negara Republil Indonesia Nomor 4774. 